\title{
Amyloid deposition and ApoE4 carriers in idiopathic normal pressure hydrocephalus
}

\author{
Masahiko Bundo ${ }^{*}$, Akinori Nakamura, Takashi Kato, Shunpei Niida, Kaori Iwata, Chihomi Sawado, Kengo Ito \\ From Hydrocephalus 2015 \\ Banff, Canada. 18-21 September 2015
}

\section{Introduction}

It is known that idiopathic normal pressure hydrocephalus (iNPH) can co-morbid with Alzheimer disease (AD). Previous studies, probing amyloid $(\mathrm{A} \beta)$ deposition by cortical biopsy during a ventriculo-peritoneal shunt, have shown that $A \beta$ deposition was found in $40 \sim 45 \%$ of iNPH patients. However, the reason for this high prevalence is not well understood. Therefore, the objective of this study was to investigate whether the prevalence of the $A \beta$ deposition in iNPH is explainable by a simple overlap of the $\mathrm{AD}$ pathology in general population, or is modified by some specific effects of iNPH.

\section{Methods}

In this study, 11C-Pittsburgh compound B (11C-PiB) $\mathrm{PET}$ and Apolipoprotein $\mathrm{E}$ genotype were examined in age- matched 70 Cognitively Normal Elderly (CNE), 19 Alzheimer disease (AD) and 31 probable iNPH patients, to investigate the risk of co-morbidity of AD in iNPH patients. The chi-square analysis was used for the statistical analysis. The Bonferroni correction was used for the multiple comparisons.

\section{Results}

Amyloid deposition was shown in 19.0\% of CNE, 81.3\% of $\mathrm{AD}$, and $52.0 \%$ of $\mathrm{iNPH}$, while ApoE4 carriers were found in $19.0 \%$ of CNE, $73.7 \%$ of $\mathrm{AD}$, and 29.0 of $\mathrm{iNPH}$. The rate of amyloid deposition of iNPH was significantly higher than CNE $(\mathrm{p}<0.005)$ and lower than AD $(\mathrm{p}<$ $0.005)$. On the other hand, the probability of the apoE4 carriers in iNPH was significantly lower than AD (p < $0.005)$, but did not show any significant difference from CNE $(\mathrm{p}=0.56)$.

* Correspondence: ibundou@ncgg.go.jp

National center for geriatrics and gerontology, Japan

\section{Conclusions}

In $\mathrm{iNPH}$, the rate of amyloid deposition is higher than $\mathrm{CNE}$, while there were no differences in the probability of the ApoE4 carriers. These results suggest that iNPH patients may have some mechanisms to facilitate the amyloid deposition.

Published: 18 September 2015

doi:10.1186/2045-8118-12-S1-P5

Cite this article as: Bundo et al:: Amyloid deposition and ApoE4 carriers in idiopathic normal pressure hydrocephalus. Fluids and Barriers of the CNS 2015 12(Suppl 1):P5.
Submit your next manuscript to BioMed Central and take full advantage of:

- Convenient online submission

- Thorough peer review

- No space constraints or color figure charges

- Immediate publication on acceptance

- Inclusion in PubMed, CAS, Scopus and Google Scholar

- Research which is freely available for redistribution
() Bïomed Central 